\title{
Development of inexpensive prosthetic feet for high-heeled shoes using simple shoe insole model
}

\author{
Margrit R. Meier, PhD; ${ }^{*}$ Kerice A. Tucker, BSc; ${ }^{2}$ Andrew H. Hansen, PhD $^{3}$ \\ ${ }^{1}$ Department of Occupational Therapy and Prosthetics and Orthotics, Faculty of Health Sciences, Oslo and Akershus \\ University College of Applied Sciences, Oslo, Norway; ${ }^{2}$ Prosthetics-Orthotics Center, Feinberg School of Medicine, \\ Northwestern University, Chicago, IL; ${ }^{3}$ Minneapolis Department of Veterans Affairs Health Care System, Minneapolis, \\ MN; and Program in Rehabilitation Sciences, Department of Physical Medicine and Rehabilitation, University of Min- \\ nesota, Minneapolis, $M N$
}

\begin{abstract}
The large majority of prosthetic feet are aimed at low-heeled shoes, with a few models allowing a heel height of up to $5 \mathrm{~cm}$. However, a survey by the American Podiatric Medical Association indicates that most women wear heels over 5 $\mathrm{cm}$; thus, current prosthetic feet limit most female prosthesis users in their choice. Some prosthetic foot components are heel-height adjustable; however, their plantar surface shapes do not change to match the insole shapes of the shoes with different heel heights. The aims of the study were therefore (1) to develop a model that allows prediction of insole shape for various heel height shoes in combination with different shoe sizes and (2) to develop and field-test low-cost prototypes of prosthetic feet whose insole shapes were based on the new model. An equation was developed to calculate insole shapes independent of shoe size. Field testing of prototype prosthetic feet fabricated based on the equation was successful and demonstrated the utility of the equation.
\end{abstract}

Key words: development, equation, feet, heel height, high heels, prosthetic feet, prototype, roll-over shape, shoe insole model, shoes.

\section{INTRODUCTION}

Changing shoes in order to accommodate for different circumstances and occasions comes naturally and hassle-free for most of us because the physiological anklefoot system accommodates automatically to a variety of heel heights (HHs). This automatic adaptation occurs primarily at the ankle, with smaller changes occurring throughout the foot, such as shifting of the toe break location more posteriorly with higher HHs and changing of the midfoot's geometry and the foot's plantar surface geometry as observed by Price [1]. Despite these changes, the natural foot-ankle system produces rollover shapes that are kept alike across the spectrum of tested heels [2]. However, for people with lower-limb amputation, the situation is different: their prosthetic limb is usually fixed to the given $\mathrm{HH}$ of the shoe worn during alignment in clinics. When the user of a prosthetic limb switches to a shoe with a different $\mathrm{HH}$, the prosthetic foot requires plantar flexion or dorsiflexion in order to maintain the correct function of the prosthesis. Small changes in $\mathrm{HH}$ produce effective changes in the alignment; these changes can be compensated for as long as they remain within a subjectspecific tolerance range [3]. But alignment changes

\footnotetext{
Abbreviations: $\mathrm{HH}=$ heel height, $\mathrm{MWA}=$ modified Witch of Agnesi (equation), WA = Witch of Agnesi (equation).

*Address all correspondence to Margrit R. Meier, PhD; Department of Rehabilitation Therapy and Prosthetics and Orthotics, Faculty of Health Sciences, Oslo and Akershus University College of Applied Sciences, Postboks 4 St Olavs Plass, 0130 Oslo, Norway; +47-22-45-25-70.

Email: Margrit-R.Meier@hioa.no

http://dx.doi.org/10.1682/JRRD.2013.01.0010
} 
influence the walking pattern of prosthesis users. For example, results of studies indicate that the ground reaction forces are sensitive to alignment changes [4-7], also influencing, among others, the contralateral, nondisabled limb as reflected in an increased maximal knee flexion angle and work load at the knee joint [8]. Thus, changing shoes with different HHs, even within the category of "flat heels," has an effect on the function of the prosthesis and the wearer's comfort.

A survey of the American Podiatric Medical Association in 2003 [9] reported that 62 percent of women wear heels over $5 \mathrm{~cm}$. Despite the documented negative effect that high heels seem to have [10-15], high-heeled shoes remain an integral part of most women's attire. To our knowledge, none of the prosthetic feet currently available on the market exceed $5 \mathrm{~cm}$, thus restricting the choice of a great majority of women using a lower-limb prosthesis. Having a choice in footwear is highly important, as outlined by studies conducted in relation to orthopedic footwear. For example, participants state that they had experienced difficulties with their footwear in relation to their employment because they sometimes could only wear sneakers at work [16]. Hendry et al. stated further that these reported difficulties were supported by a statement from a consultant within the rheumatologist's focus group who mentioned that at times, her client would rather be in a wheelchair than wearing shoes that did not look right [16]. This might be an extreme view, but it highlights the importance of being able to wear shoes that are adequate for a given occasion. Williams et al. went a step further and included patients' opinions in the design process of customized orthopedic shoes to test its effect on various foot-related problems, including compliance [17]. The study's results showed that real opportunities to influence the design process for custom-made shoes significantly improved foot function (effect on physical function), foot pain (severity and duration), general foot health (self-perception of body image in relation to participants' feet), physical activity, and patient compliance [17-19]. This shows that having a choice, being able to make a decision, and thus-in a wider sense-having influence on one's daily life is crucial, with direct and significant implications on health.

No study was found analyzing the effects of different HHs in persons with lower-limb amputation. However, clinical observations reveal that for persons using lowerlimb prostheses, changes in HH interfere with their walking abilities. These changes may be difficult to compen- sate for and thus remain frustrating. Mechanical testing of prosthetic feet with different HH shoes show changes in the effective alignment of the rollover shapes, supporting the clinical observations [20].

The few prosthetic components on the market allowing adjustments for shoes of different HHs do not alter the plantar surface shape of the foot to match the corresponding insole shapes. For example, with increasing $\mathrm{HH}$, the toe spring, i.e., the height difference of a shoe's toe sole region to the floor, may increase, whereas the location of the toe break, i.e., the location where a shoe starts to bend, shifts posteriorly, as highlighted by Price [1]. Therefore, for shoes of significant $\mathrm{HH}$, a mismatch between prosthetic foot plantar geometry and shoe insole shape could be a source of instability for a prosthesis user and lead to early failure of the prosthetic foot, shoe, or both.

The purpose of this study was to develop a model that allows prediction of an insole shape for various $\mathrm{HH}$ shoes in order to increase the range of currently available HHs for women with lower-limb amputation. To determine the utility of the model, a series of inexpensive prosthetic foot cores were developed, basing their functionality on the roll-over shape principle [21]. These newly developed prosthetic foot cores were named Shape\&Roll Talon. ${ }^{*}$ They were tested (mechanically and in the clinic with a custom-made silicone cosmetic shell) in conjunction with a method of quickly changing foot and shoe combinations instead of changing shoes and alignment of the prosthetic foot.

\section{METHODS}

This article describes a five-step development process for a model to predict the insole shape of a prosthetic foot for a desired $\mathrm{HH}$ at a given shoe size. Each step, explained in more detail later, builds on the previous step by using its results as input (Figure 1).

Because such a development procedure follows only in part the classic divided presentation of "methods" and "results," we prefer to present results also in the "Methods" section for ease of understanding. Therefore, the methods for step 1 (analysis), step 2 (verification), step 3 (mathematical description), and step 4 (transfer) are presented together with their corresponding results. For

*Talon is French for "heel.” 


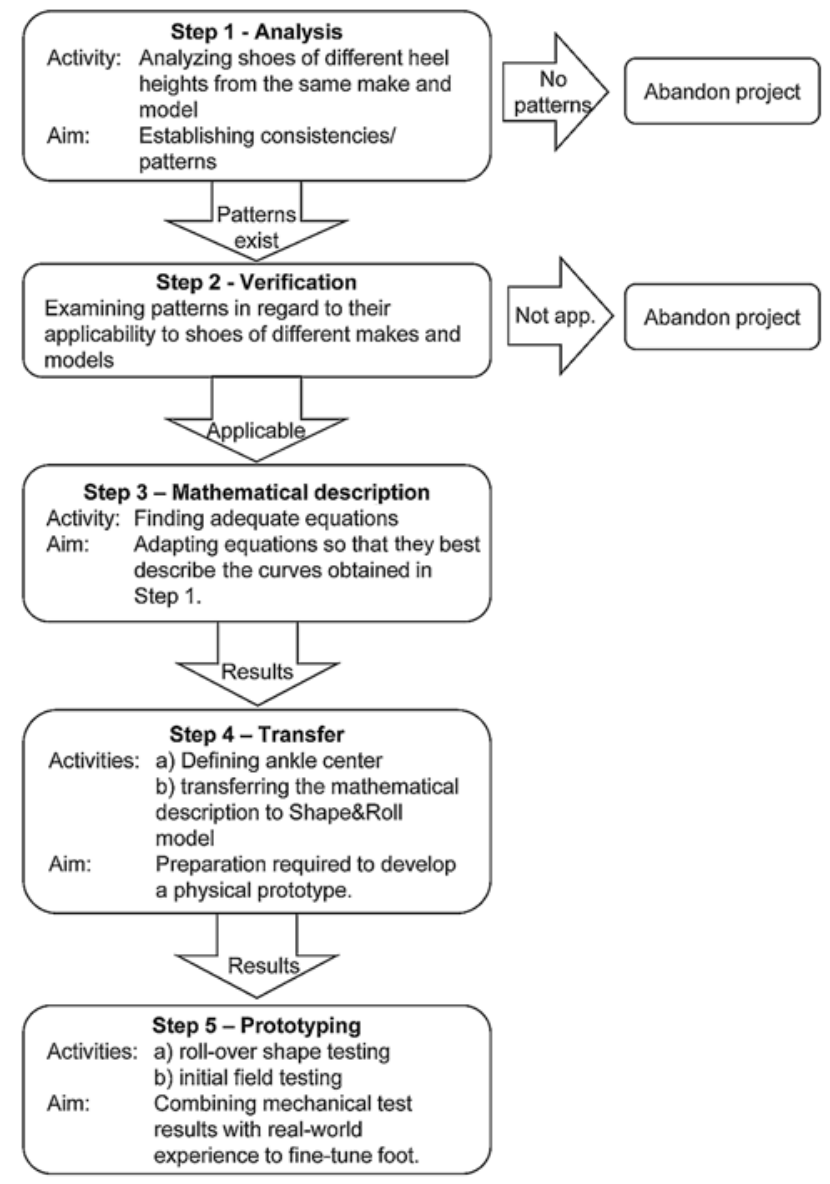

Figure 1.

Flowchart of proposed method.

step 5 (prototyping), whose methods follow in the more traditional manner, the results are presented within the "Results" section.

\section{Step 1: Analysis}

In order to analyze whether there exists a consistent relationship between insole shape and shoe size for a given $\mathrm{HH}$, three pairs of shoes of the same model and make were purchased in three different sizes (UK 3, 5, and 7) but with similar absolute $\mathrm{HH}(6 \mathrm{~cm})$. The shoes were all from the same manufacturer and of the same model and make in order to reduce confounding variables for this initial step. They are referred to here as "model shoes." The absolute HH is the difference between the thickness of the sole at the heel and the thickness of the sole beneath the metatarsal heads. The insole shapes of the model shoes were digitized in the sagittal plane only, and the resulting $x$ and $y$ coordinates were plotted. From the model shoes, we observed that the insole shape for a specific $\mathrm{HH}$ appeared to be independent of the shoe size (Figure 2), with different lengths in the heel and toe regions for different sizes.

\section{Step 2: Verification}

First, to verify whether this independency of insole shape and shoe size for a given $\mathrm{HH}$ could be confirmed in other shoe makes and models, and second, to test whether this independency exists regardless of the $\mathrm{HH}$, an additional 12 pairs of randomly chosen shoes of different makes and models from several manufacturers were purchased at various sizes (US 6.5, 7.5, and 9, and UK 4.5, 5.5, and 7) and with HHs ranging from 2 to $7 \mathrm{~cm}$. These 12 pairs were analyzed in the same way as the model shoes. Visual inspections confirmed that within the range of the selected shoe sizes, shoes of similar HH exhibit the same insole shape from one size to the next, regardless of manufacturer, model, or make (Figure 3).

The finding of this consistent relationship between foot sizes simplifies the model considerably because foot length no longer must be considered as a variable. This finding allowed searching for a mathematical description of the obtained curves, i.e., the digitized insole shapes in the sagittal plane, which could predict any desired insole shape for $\mathrm{HH}$ within the given range from 0 to $7 \mathrm{~cm}$.

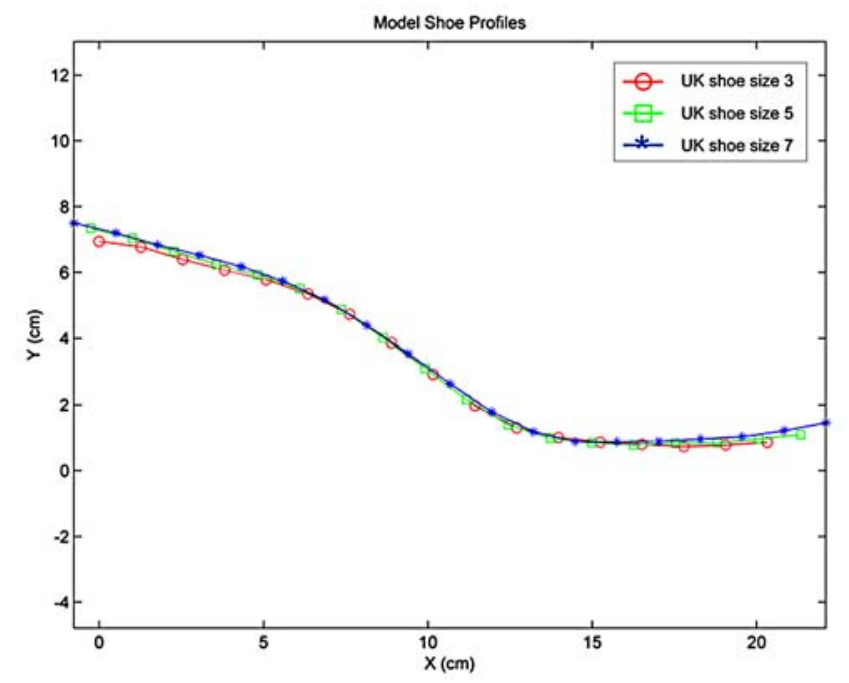

Figure 2.

Insole shapes of three model shoes seem to be the same despite different shoe sizes. 

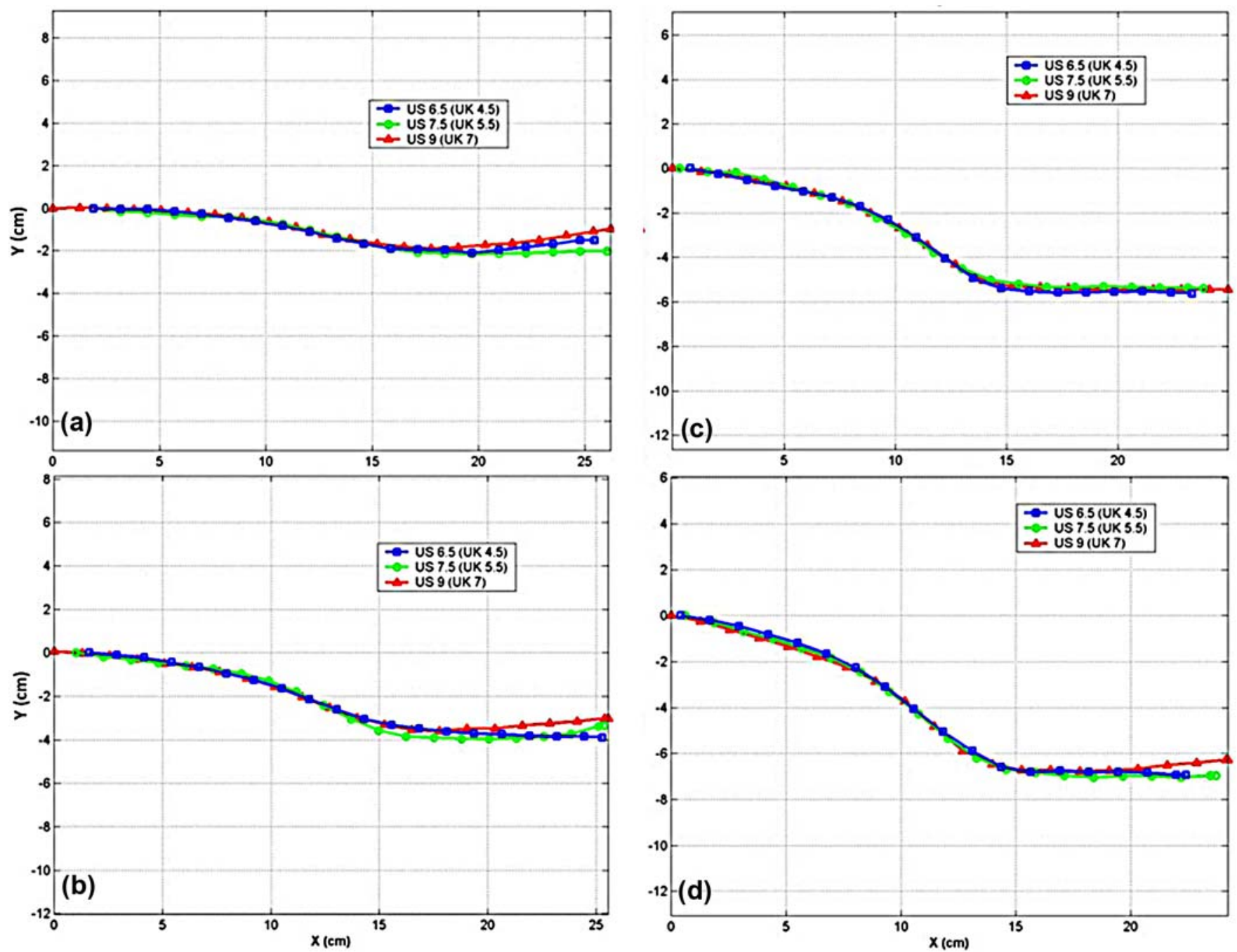

Figure 3.

Sagittal plane insole shape profiles of shoes in different sizes but with same heel height (HH): (a) $2 \mathrm{~cm}$, (b) $4 \mathrm{~cm}$, (c) $5.5 \mathrm{~cm}$, and (d) $7 \mathrm{~cm}$. In each of these four $\mathrm{HH}$ categories, three shoes of different manufacturers and make were measured.

\section{Step 3: Mathematical Description}

From a mathematical point of view, high-heeled shoes can be divided into two regions: a nonlinear arch and toe region and an approximately linear heel region. For the arch and toe region, the simplest form of the Witch of Agnesi (WA) equation (Equation (1)) was used as a starting point for describing the corresponding nonlinear profile of the shoe insole curves:

$$
y=\frac{1}{x^{2}+1}
$$

The WA equation was chosen after exploring the characteristics of the function and realizing that slight modifications could allow it to fit the shoe insole profiles. Adjustments were made to this equation in an iterative fashion until the equation best fit the insole profiles of the shoes, resulting in the modified Witch of Agnesi (MWA) equation.

For the heel region, a simple linear curve could be used. A linear equation was created by measuring the slopes of the model shoes' heel portion and plotting the resulting values against their corresponding HHs. A linear 
regression was used to arrive at the relationship between the heel slope and HH (Equation (2)):

$$
m \approx \frac{-H H}{24} .
$$

The slope $(m)$ was derived to begin at the back end of the size UK 3 model shoe $(x=0 \mathrm{~cm})$ and descend to meet the second section of the MWA equation at $x=6.5 \mathrm{~cm}$, a location also found to correspond with the ankle center.

The obtained model now consists of two parts (Equation (3)): a linear portion that defines the heel region (part 1) and a nonlinear portion, the MWA, that defines the arch and toe regions (part 2) of a shoe's insole profile. Part 1 is used in the heel region $(-2 \mathrm{~cm} \leq x<6.5 \mathrm{~cm})$; part 2 is used in the forefoot region $(x \geq 6.5 \mathrm{~cm})$ :

$$
y=\left\{\begin{array}{cc}
\text { 1) } & m \times x \\
\text { 2) } & \frac{-H H}{(x-22.4)^{6}}+1 \\
& \left(6 \times 10^{6}\right)
\end{array}\right.
$$

where $\mathrm{HH}$ is measured in centimeters, $m$ is a constant as derived from Equation (2), and $x$ and $y$ describe the sagittal profile of the shoe insole in Cartesian coordinates, also expressed in centimeters. Figure $\mathbf{4}$ shows the plotted MWA for HHs between 0 and $7 \mathrm{~cm}$. The transition between the two parts occurs at the ankle center $(x=6.5 \mathrm{~cm})$.

Figures 5(a) to 5(d) show the accuracy of the model's prediction in relation to the digitized insoles presented in Figure 3. Each predicted sole well matched the corresponding sizes of every $\mathrm{HH}$. Visual verification reveals that the model seems to predict the shapes of the insoles of 50 percent of the shoes (i.e., 6 out of 12 pairs) quite accurately.

This was the case for shoe size US 7.5 at $2 \mathrm{~cm} \mathrm{HH}$ (Figure 5(a)); shoe sizes US 6.6, 7.5, and 9 at $5.5 \mathrm{~cm} \mathrm{HH}$ (Figure 5(c)); and shoe sizes US 6.5 and 7.5 at $7 \mathrm{~cm} \mathrm{HH}$ (Figure 5(d)). For another 33 percent (i.e., 4 out of 12 pairs), the model only strayed from the actual data in the toe region due to each shoe designer's individual applied toe spring. These were shoe sizes US 6.5 and 9 at $2 \mathrm{~cm}$ $\mathrm{HH}$ (Figure 5(a)), shoe size US 7.5 at $4 \mathrm{~cm} \mathrm{HH}$ (Figure 5(b)), and shoe size US 9 at $7 \mathrm{~cm} \mathrm{HH}$ (Figure 5(d)). For the remaining 17 percent (i.e., 2 out of 12 pairs), one pair of shoes had a $0.5 \mathrm{~cm}$ lower $\mathrm{HH}$ than its actual classification (Figure 5(b), shoe size US 9), and the other pair had

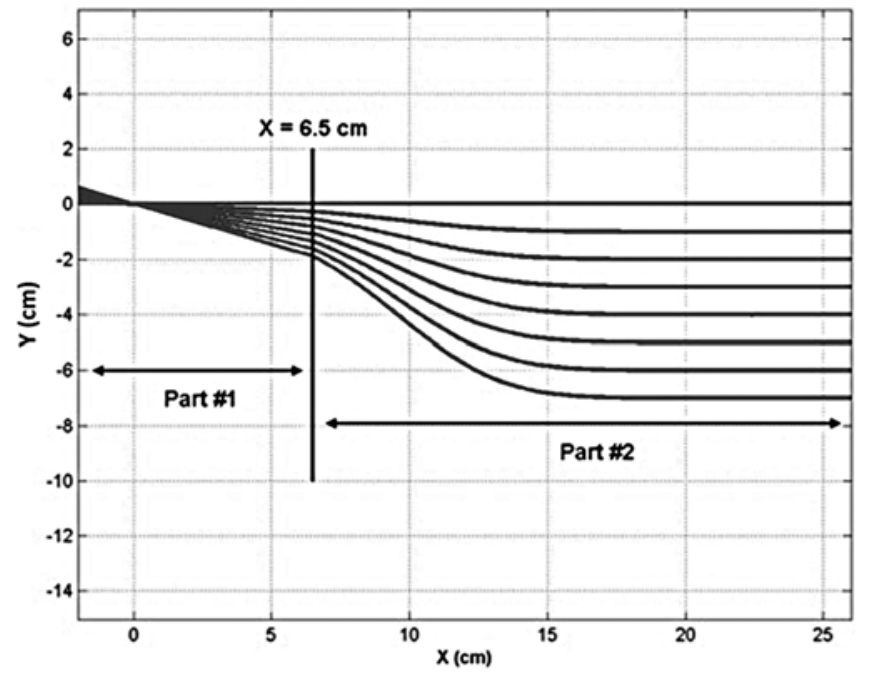

Figure 4.

Plotted insole profiles for heel heights ranging from 0 to $7 \mathrm{~cm}$ using modified Witch of Agnesi equation.

a nonstandard insole profile with its lowest point occurring at the tip of the toe instead at the level of the metatarsal heads (Figure 5(b), shoe size US 6.5).

\section{Step 4: Transfer}

The results of step 3 (Figure 5) show that the predictions obtained by the model are sufficient to move forward. The point has therefore been reached where the transfer from the theoretical to the physical environment could be made. The Shape\&Roll Talon's basic design consists of three key parts required for fabricating a first prototype: (1) a sole predicted by the model described in step 3, (2) a flat ankle region with its corresponding ankle center essential for attaching the prosthetic foot adapter (e.g., a pyramid adapter), and (3) a downward-sloping, concave keel region that merges with the top surface of the insole shape (Figure 6(a)).

The length of the flat ankle region was determined as the minimum needed to accommodate an Ottobock foot adapter (2R31=M10, Ottobock; Duderstadt, Germany). To determine concave keel region shapes, we first digitized a series of photographs of a woman's foot in shoes (shoe size US 7.5) of different HHs (Figure 7(a)).

Through trial and error, we determined that rotated cosine functions could provide forefoot keel regions that would fit within the digitized foot outlines for a series of 

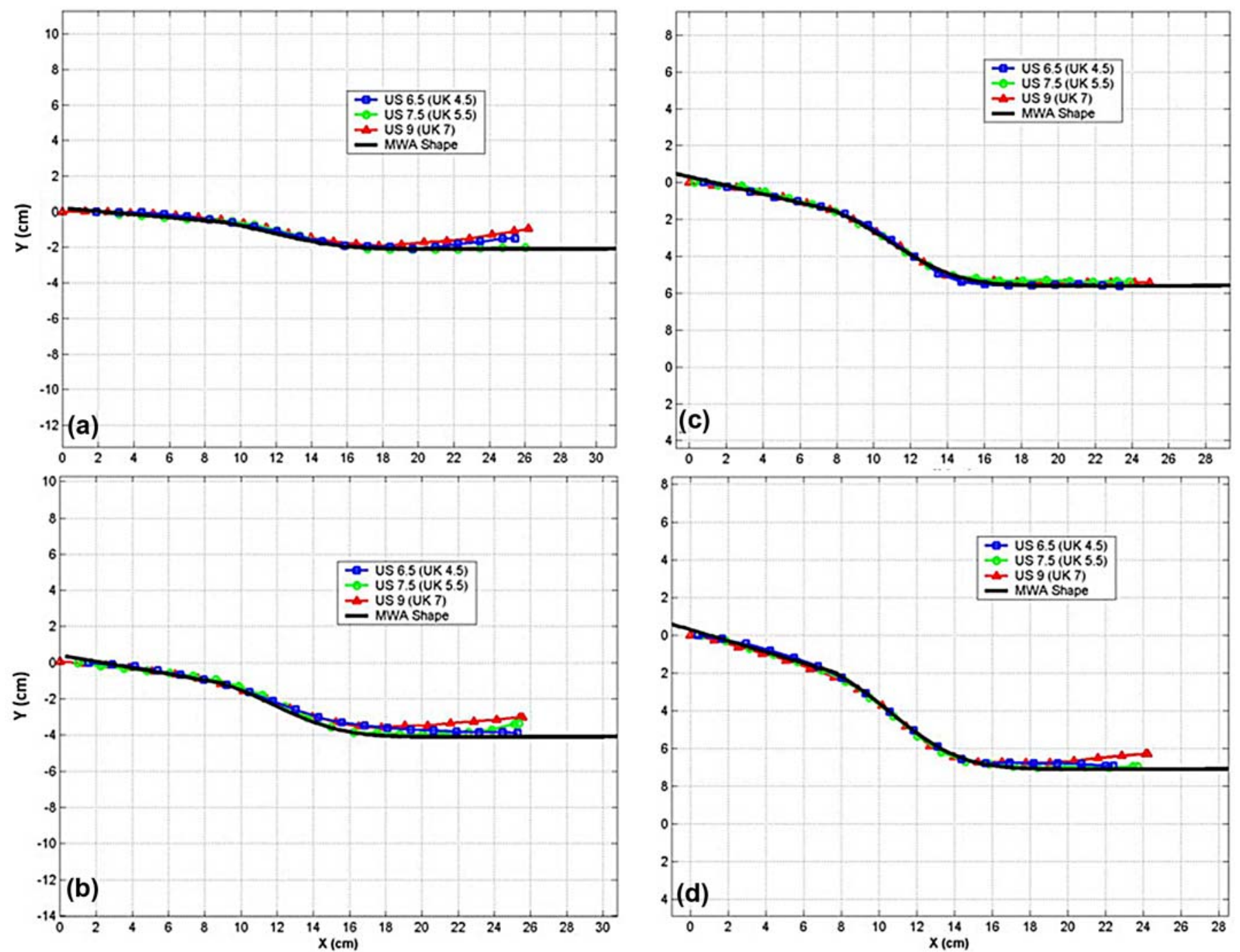

Figure 5.

Predicted curve obtained by modified Witch of Agnesi (MWA) equation in relation to sagittal plane insole shapes shown in Figure 1. Heel height categories: (a) $2 \mathrm{~cm}$, (b) $4 \mathrm{~cm}$, (c) $5.5 \mathrm{~cm}$, and (d) $7 \mathrm{~cm}$.

HHs (Figure 7(b)), a necessary constraint for provision of a cosmetically realistic system in the future.

The last step for manufacturing the Shape\&Roll Talon was to determine the locations of the opening in the forefoot keel regions to provide the biomimetic roll-over shape during walking. This step was accomplished using an iterative computer program, similar to that used for the Shape\&Roll prosthetic foot [21]. The openings were created into forefoot keels of the feet using a band saw blade.

\section{Step 5: Prototyping}

\section{Roll-Over Shape Testing of Prototypes}

The functionality of the Shape\&Roll Talon foot is based on the roll-over shape, a principle previously successfully applied to a low-cost prosthetic foot [21-22]. The roll-over shape is the effective rocker shape that the foot-ankle system conforms to between the heel contact of one limb and the heel contact of the contralateral limb [2]. In young nondisabled persons, the roll-over shape has been shown to conform to a rocker shape with a 

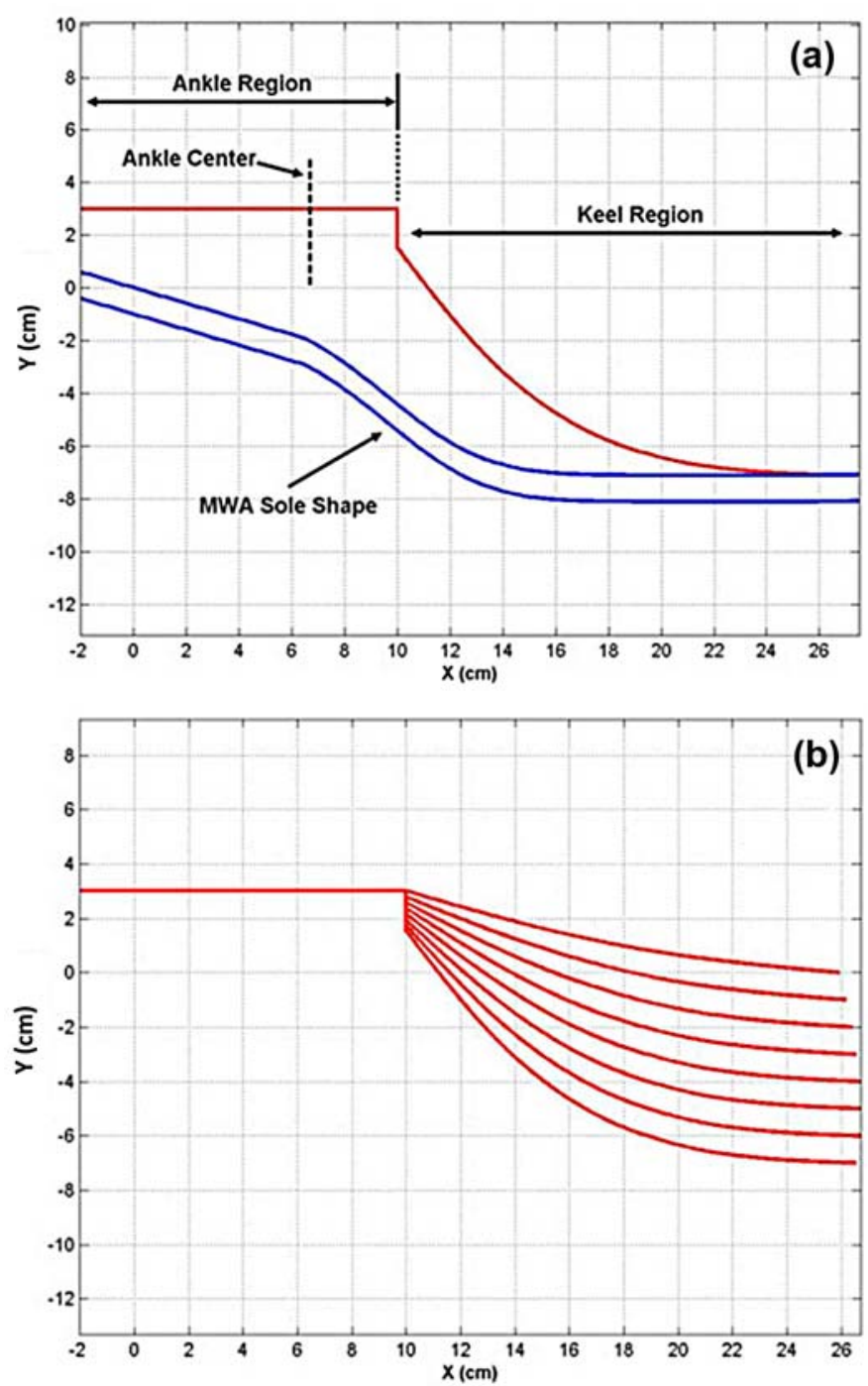

Figure 6.

(a) Three key parts of Shape\&Roll Talon prosthetic foot: ankle region, modified Witch of Agnesi (MWA) equation sole shape, and keel region. (b) Profiles of ankle and keel regions at heel heights of 0 to $7 \mathrm{~cm}$.

radius of about one-third of the leg length [23]. In addition, the radius of the roll-over shape stays consistent for level walking conditions, including walking at different speeds [24], while carrying added weights to the trunk [25], and while walking with different footwear [26], making it a useful tool for the development of prosthetic feet. The goal for the Shape\&Roll Talon foot was therefore to mimic as closely as possible the physiological
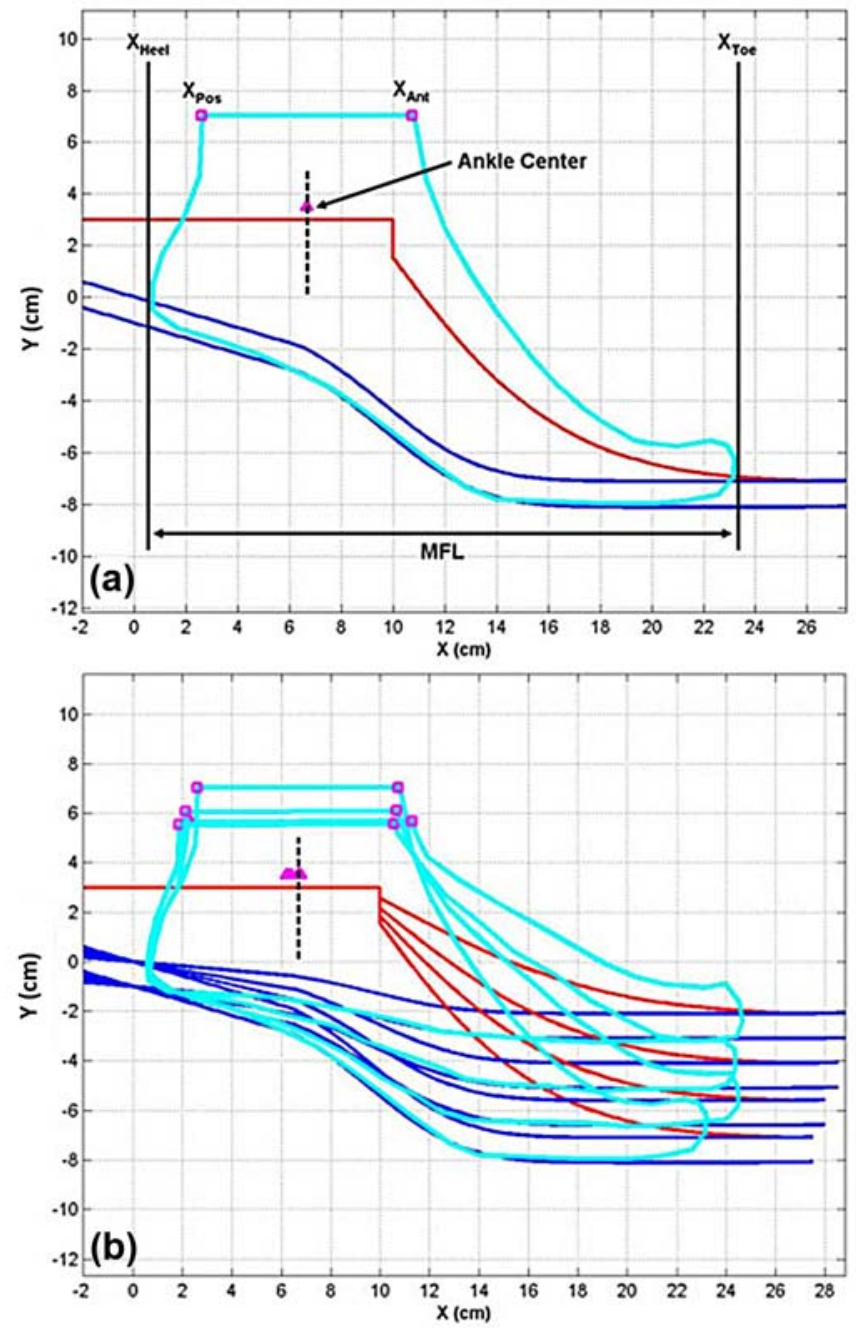

Figure 7.

(a) Foot outline for $5 \mathrm{~cm}$ heel height $(\mathrm{HH})$ shoe with Shape\&Roll Talon design overlaid. (b) Similar foot outlines and Shape\&Roll Talon designs for four different HHs. Parallel sole shape lines indicate thickness of Shape\&Roll Talon's sole plate. Ant $=$ anterior, $\mathrm{MFL}=$ modified foot length, Pos = posterior.

roll-over shape by using a similar concept as for the original Shape\&Roll prosthetic foot.

In order to verify the intended functional properties of the Shape\&Roll Talon, we tested the roll-over shape of a $7 \mathrm{~cm} \mathrm{HH}$ prototype, with an overall foot size of $25 \mathrm{~cm}$. Based on our experiences with many years of work on Shape\&Roll feet at $\mathrm{HH}=0 \mathrm{~cm}$, we were confident that we could obtain the appropriate roll-over shape. We 
therefore decided to test the highest $\mathrm{HH}$ in combination with the shortest adult foot size to determine whether our adapted algorithm was working properly, assuming that HHs between these extremes should also work as expected.

The roll-over shapes were measured using a threemarker system (Figure 8) with an eight-camera motion analysis laboratory (Motion Analysis Corporation; Santa Rosa, California) and one force plate (AMTI; Watertown, Massachusetts).

The measurements were collected at a low load level of $534 \mathrm{~N}$, using visual feedback of the force allowing for a uniform loading that would be characteristic of slow walking forces [27]. Three trials were collected, and the resulting data were used to determine the Shape\&Roll Talon's roll-over shape and corresponding radii as described in an earlier work [24].

\section{Initial Field-Testing of Prototypes}

Participants. For the initial field-testing of the Shape\&Roll Talon prototypes, a convenience sample of three women with unilateral transtibial amputation was chosen. The participants were recruited through a flyer sent to all members of The Murray Foundation, an orga-

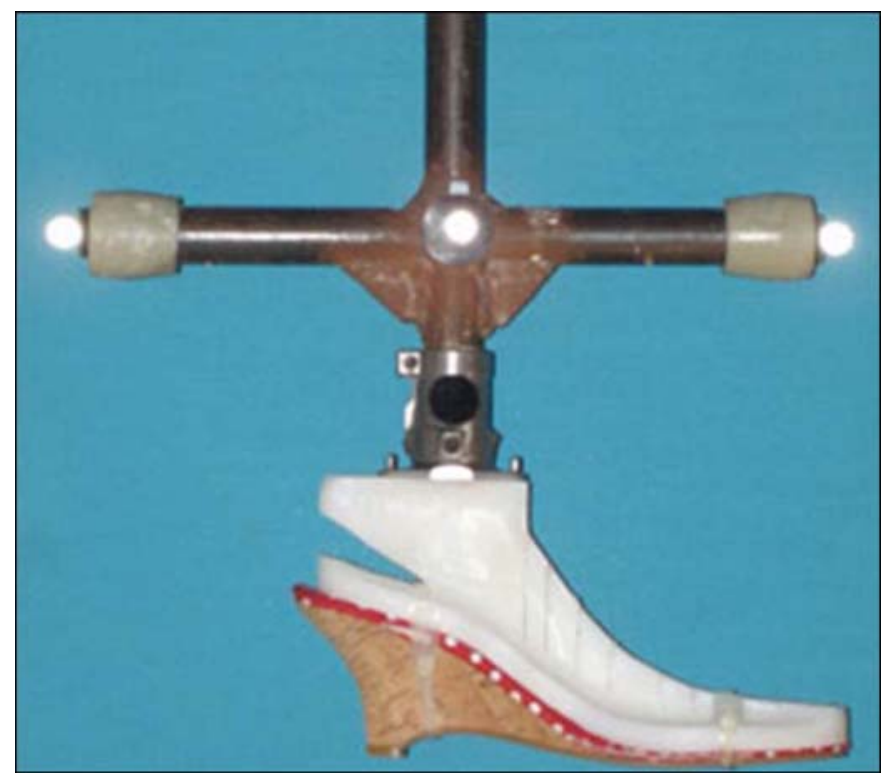

Figure 8.

Three marker system used to measure roll-over shape of Shape\&Roll Talon. Test foot's core was secured to shoe base using plastic cable ties. nization established as a support service for those affected by limb loss or absence in Scotland. In order to participate, the interested candidates needed to be aged between 18 and $65 \mathrm{yr}$, have a unilateral transtibial amputation without serious complications that interfere with walking abilities, have $\geq 12$ mo experience with a definitive prosthesis, be able to walk unassisted at a comfortable speed without undue fatigue and without health risk, and have good cognitive abilities. Poor current prosthetic fit that reduced control over the prosthesis and persons with partial paralysis due to stroke or traumatic injuries were excluded from the study.

Protocol. The participants received a testing prosthesis with a prosthetic socket as a duplicate of their current prosthetic socket and three testing feet, each with different HHs. Each participant was requested to bring her choice of shoes: one ordinary, flat-heeled shoe and two shoes with different HHs up to a maximum of $7 \mathrm{~cm}$. We developed and constructed a wooden compression molding lever device for the fabrication of the Shape\&Roll Talon prototypes. The feet were fabricated such that the participants could interchange them without interference of the original alignment of the testing prosthesis. Larger and smaller sized feet were manufactured by cutting less or more off of the heel and toe regions of the Shape\&Roll Talon foot design described earlier. Each testing foot received a handmade customized silicone cosmetic foot shell. The testing period was $5 \mathrm{wk}$, and the participants were encouraged to change feet as many times as they desired. At the end of the testing session, an in-house questionnaire was administered in order to assess the design's feasibility and function (Appendix, available online only). Only observational gait analysis was performed.

\section{RESULTS}

\section{Roll-Over Shapes and Radii}

We tested a $25 \mathrm{~cm}$ foot with a $7 \mathrm{~cm} \mathrm{HH}$ (Figure 9). The roll-over shapes obtained were smooth and visually similar to previously presented roll-over shapes [23]. The desired biomimetic radius would be approximately 1.25 times the foot length, i.e., $31.25 \mathrm{~cm}$. For the loading level tested (534 N), we received a mean \pm standard deviation radius of the roll-over shapes of $32.3 \pm 0.2 \mathrm{~cm}$. The minimum radius was $32.10 \mathrm{~cm}$, and the maximum was $32.40 \mathrm{~cm}$ (Table 1).

The location of the center of rotation for the best fit arc is forward positioned when compared with the shank 


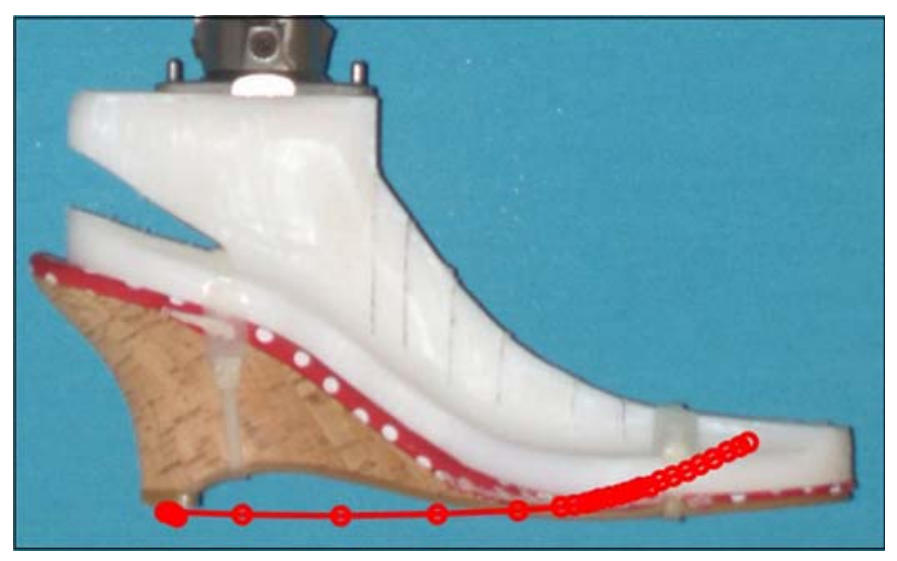

Figure 9.

Roll-over shape superimposed over tested $25 \mathrm{~cm}$-long prototype core at load level of $534 \mathrm{~N}$.

reference frame. The obtained mean forward position was $2.6 \pm 0.1 \mathrm{~cm}$. The desired forward shift is 0.066 times the foot length [28]. In our case, where a $25 \mathrm{~cm}$ foot was tested, the desired forward shift would have been $1.65 \mathrm{~cm}$. The obtained results represent a small overshoot of 3.36 percent from the desired biomimetic roll-over shape radius and a $1 \mathrm{~cm}$ difference in forward shift position. These changes are within the range of variation in biomimetic properties and could likely be accounted for during the alignment process [28].

\section{Field-Testing}

The three participants, aged between 51 and $65 \mathrm{yr}$ (Table 2), were enthusiastic about the project and brought some shoes with challenging heels, for example, a set-back heel or a narrow, tapered-down base, ending in a heel base of support of roughly $1 \mathrm{~cm}^{2}$.

Based on the questionnaire's result, the participants changed their feet on average three times per week, ranging from once per week to twice a day. They indicated

Table 1.

Radius and location of center of rotation.

\begin{tabular}{lcc}
\hline Trial & $\begin{array}{c}\text { Radius } \\
(\mathbf{c m})\end{array}$ & $\begin{array}{c}\text { Location of Center } \\
\text { of Rotation } \\
(\mathbf{c m})\end{array}$ \\
\hline 1 & 32.4 & 2.6 \\
2 & 32.3 & 2.6 \\
3 & 32.1 & 2.5 \\
Mean \pm SD & $32.3 \pm 0.2$ & $2.6 \pm 0.1$ \\
\hline \multicolumn{2}{l}{ SD = standard deviation. } \\
\hline \hline
\end{tabular}

not requiring more attention when walking outside while wearing the higher-heeled shoes, although they stated sometimes using a cane or stick when walking over uneven or rough terrain. No assistance was required when walking indoors. In regard to preference of the $\mathrm{HH}$, participant 2 liked all her heels ranging from 2 to $5 \mathrm{~cm}$, participant 1 preferred walking with middle-height heels of $3 \mathrm{~cm}$, and participant 3 preferred walking on high heels of $6 \mathrm{~cm}$. The participants wore their favorite heels 67 percent of the time during the testing period. Compared with her usual prosthetic foot, participant 1 felt the Shape\&Roll Talon introduced a limp when she walked on her highest heel $(6 \mathrm{~cm})$. Participant 2 experienced all test feet as rolling over very naturally and smoothly, whereas participant 3 indicated that the feet were not as supple at first, but that she got used to it. On average, the participants did not feel any change in weight with the testing prosthesis and considered their walking style as excellent, with slight deviations when compared with nondisabled persons. They felt that their walking style was not changed while wearing the testing prosthesis. However, participant 2 indicated that her walking style and abilities improved largely, but this might be more related to a pain-free prosthetic socket based on an improved alignment with the testing prosthesis than due to the prosthetic feet she was testing. In general, the participants were delighted with the concept and were happy to have had the opportunity to trial the prototypes.

\section{DISCUSSION}

The goal of the study was to develop a model that allows prediction of insole shapes for prosthetic feet for various different HHs. The profile of an insole shape changes depending on the $\mathrm{HH}$, i.e., the insole shape of a shoe with a high heel is different from the insole shape of a shoe with a low or flat heel. The current few prosthetic feet that exist on the market that allow adapting to different HHs do so by changing plantar flexion and dorsiflexion orientation only. Their insole shapes, however, remain unchanged and can have a destabilizing effect due to improper fit inside a shoe. The discrepancy between the sole of the prosthetic foot and the insole shape of the corresponding shoe could affect the durability of a prosthetic foot, the shoe, or both.

The model developed consists of an MWA equation and a linear equation, adapted algorithms that describe 
JRRD, Volume 51, Number 3, 2014

Table 2.

Sociodemographic information of three participants.

\begin{tabular}{lccc}
\hline & \multicolumn{1}{c}{ Variable } & \multicolumn{1}{c}{ Participant } & $\mathbf{3}$ \\
\cline { 2 - 4 } & \multicolumn{1}{c}{$\mathbf{1}$} & 65 & 60 \\
Age (yr) & 51 & 1.68 & 1.67 \\
Height (m) & 1.62 & 89 & 70 \\
Weight (kg) & 89 & Right & Right \\
Amputation Side & Left & Iceross & Iceross \\
Current Prosthetic Socket & Iceross & Ottobock 1C30 Trias & Ottobock Dynamic Foot \\
Current Prosthetic Foot & Blatchford & \\
\hline \hline
\end{tabular}

the shape of the insoles for $\mathrm{HHs}$ ranging from 0 to $7 \mathrm{~cm}$. The results of the model were compared with digitized insole shapes and tested in a pilot field test. There were two areas in which the MWA model deviated from the digitized insole shapes. The first area is seen at the $4 \mathrm{~cm}$ $\mathrm{HH}$ in the metatarsal region: the size US 6.5 shoe (indicated by a closed circle) has a nonstandard shape. Of the measured shoes, 92 percent displayed the lowest point of their profile at the metatarsal heads, with varying degrees of toe springs afterward. However, this shoe's profile reaches its lowest point at the tip of the toe instead at the metatarsal heads. A better fit for this particular profile would probably be a prediction based on a lower $\mathrm{HH}$, slightly plantar flexed. The size US 9 shoe also does not match the predicted shape due to the shoe having a slightly smaller $\mathrm{HH}$ than $4 \mathrm{~cm}$. A better fit for this shoe would be an MWA equation shape based on a $3.5 \mathrm{~cm} \mathrm{HH}$. These two instances highlight the importance of carefully measuring a shoe's HH and analyzing its profile.

The second area where some shoes deviate from the predicted MWA equation sole shapes is in the toe region: no clear pattern in relation to $\mathrm{HH}$ or shoe size seems to be present for the toe spring. For example, a clear pattern would be that the toe spring increases with $\mathrm{HH}$ or that the toe spring increases with shoe size across all HHs. Those types of patterns can be modeled, but the randomness of the toe spring's presence prevents such modeling with any confidence. Hence, without any clear pattern, modeling the toe spring was therefore not included in the MWA equation model. For those shoes that possess some amount of toe spring, this is not a problem given that most high-heeled shoes are flexible enough within the toe box to adjust to the MWA equation-based foot's lack of toe spring. For those shoes that lack flexibility in the toe box, the sole of the MWA equation-based foot can be machined or manually cut to yield some toe spring for the foot.
A limitation of the described work is the use of visual inspection of data to examine the goodness of fit between the developed model and the digitized shoe sole data. Other approaches are possible to provide a more quantitative measure of goodness of fit, and these approaches could be used in future work if the current model requires improvement or refinement.

\section{CONCLUSIONS}

The mathematical model developed allowed for the prediction of insole shapes for various HHs ranging from 0 to $7 \mathrm{~cm}$. Within the given $\mathrm{HH}$ restriction, the model is applicable for all combination of HHs, independent of shoe size. In addition, the model is easy to implement, hopefully allowing manufacturers of prosthetic feet to increase the current $\mathrm{HH}$ of prosthetic feet on the market to $7 \mathrm{~cm}$. The first testing of prototypes, including a silicone custom-made cosmetic shell, confirmed that the concept is successful in practice, with participants delighted to change feet while maintaining prosthetic alignment. However, further development is required in order to bring the current concept into a stage where mass production would be feasible.

\section{ACKNOWLEDGMENTS}

\section{Author Contributions:}

Study concept and design: M. R. Meier.

Acquisition of data: K. A. Tucker, M. R. Meier, A. H. Hansen. Analysis and interpretation of data: K. A. Tucker, A. H. Hansen, M. R. Meier.

Drafting of manuscript: M. R. Meier.

Critical revision of manuscript for important intellectual content: M. R. Meier, A. H. Hansen, K. A. Tucker.

Obtained funding: M. R. Meier. 
Financial Disclosures: The authors have declared that no competing interests exist.

Funding/Support: This material was based on work supported by a Marie Curie International Reintegration grant (MIRG-CT-2007046445) within the 6th European Community Framework Programme. We acknowledge the use of the Motion Analysis Research Laboratory of the Jesse Brown Department of Veterans Affairs Medical Center, Chicago, Illinois.

Additional Contributions: We thank the three test candidates for their enthusiastic participation in the field-testing of our prototypes. Further, we acknowledge the technical work carried out by Mr. Jake Duers and the clinical assistance provided by Dr. Anthony McGarry, both at the University of Strathclyce, Glasgow, Scotland, United Kingdom.

Institutional Review: This study was approved by the University Ethics Committee of the University of Strathclyde, Glasgow, Scotland, United Kingdom. Written informed consent was obtained from each participant.

Participant Follow-Up: No plans to inform the participants of the publication of this study were made. Participants met with the investigators and discussed their experience and insights in regard to the field-testing.

\section{REFERENCES}

1. Price AE. Technical note: Interchangeable feet. J Prosthet Orthot. 1991;3(4):201-5.

2. Hansen AH, Childress DS. Effects of shoe heel height on biologic rollover characteristics during walking. J Rehabil Res Dev. 2004;41(4):547-54. [PMID:15558383] http://dx.doi.org/10.1682/JRRD.2003.06.0098

3. Zahedi MS, Spence WD, Solomonidis SE, Paul JP. Alignment of lower-limb prostheses. J Rehabil Res Dev. 1986; 23(2):2-19. [PMID:3723422]

4. Chow DH, Holmes AD, Lee CK, Sin SW. The effect of prosthesis alignment on the symmetry of gait in subjects with unilateral transtibial amputation. Prosthet Orthot Int. 2006;30(2):114-28. [PMID:16990222] http://dx.doi.org/10.1080/03093640600568617

5. Geil MD, Lay A. Plantar foot pressure responses to changes during dynamic trans-tibial prosthetic alignment in a clinical setting. Prosthet Orthot Int. 2004;28(2):105-14. [PMID:15382804] http://dx.doi.org/10.1080/03093640408726695

6. Van Velzen JM, Houdijk H, Polomski W, Van Bennekom CA. Usability of gait analysis in the alignment of trans-tibial prostheses: A clinical study. Prosthet Orthot Int. 2005;29(3): 255-67. [PMID:16466155] http://dx.doi.org/10.1080/03093640500238857

7. Yang L, Solomonidis SE, Spence WD, Paul JP. The influence of limb alignment on the gait of above-knee amputees. J Biomech. 1991;24(11):981-97. [PMID:1761584] http://dx.doi.org/10.1016/0021-9290(91)90016-G
8. Beyaert C, Grumillier C, Martinet N, Paysant J, André J-M. Compensatory mechanism involving the knee joint of the intact limb during gait in unilateral below-knee amputees. Gait Posture. 2008;28(2):278-84. [PMID:18295487] http://dx.doi.org/10.1016/j.gaitpost.2007.12.073

9. American Podiatric Medical Association. High heel survey. Bethesda (MD): American Podiatric Medical Association; 2003.

10. Hong WH, Lee YH, Chen HC, Pei YC, Wu CY. Influence of heel height and shoe insert on comfort perception and biomechanical performance of young female adults during walking. Foot Ankle Int. 2005;26(12):1042-48. [PMID:16390637]

11. Csapo R, Maganaris CN, Seynnes OR, Narici MV. On muscle, tendon and high heels. J Exp Biol. 2010;213(Pt 15): 2582-88. [PMID:20639419] http://dx.doi.org/10.1242/jeb.044271

12. Simonsen EB, Svendsen MB, Nørreslet A, Baldvinsson HK, Heilskov-Hansen T, Larsen PK, Alkjær T, Henriksen M. Walking on high heels changes muscle activity and the dynamics of human walking significantly. J Appl Biomech. 2012;28(1):20-28. [PMID:22431211]

13. Kerrigan DC, Johansson JL, Bryant MG, Boxer JA, Della Croce U, Riley PO. Moderate-heeled shoes and knee joint torques relevant to the development and progression of knee osteoarthritis. Arch Phys Med Rehabil. 2005;86(5): 871-75. [PMID:15895330] http://dx.doi.org/10.1016/j.apmr.2004.09.018

14. Mika A, Oleksy L, Mika P, Marchewka A, Clark BC. The effect of walking in high- and low-heeled shoes on erector spinae activity and pelvis kinematics during gait. Am J Phys Med Rehabil. 2012;91(5):425-34. [PMID:22311060] http://dx.doi.org/10.1097/PHM.0b013e3182465e57

15. Tedeschi Filho W, Dezzotti NR, Joviliano EE, Moriya T, Piccinato CE. Influence of high-heeled shoes on venous function in young women. J Vasc Surg. 2012;56(4):1039-44. [PMID:22483354] http://dx.doi.org/10.1016/j.jvs.2012.01.039

16. Hendry GJ, Turner DE, Lorgelly PK, Woodburn J. Room for improvement: patient, parent, and practitioners' perceptions of foot problems and foot care in juvenile idiopathic arthritis. Arch Phys Med Rehabil. 2012;93(11):2062-67. [PMID:22842484]

http://dx.doi.org/10.1016/j.apmr.2012.07.007

17. Williams AE, Rome K, Nester CJ. A clinical trial of specialist footwear for patients with rheumatoid arthritis. Rheumatology. 2007;46(2):302-7. [PMID:16877461] http://dx.doi.org/10.1093/rheumatology/kel234

18. Williams AE, Nester CJ. Patient perceptions of stock footwear design features. Prosthet Orthot Int. 2006;30(1):61-71. [PMID:16739782] http://dx.doi.org/10.1080/03093640600574425 
19. van Netten JJ, Jannink MJ, Hijmans JM, Geertzen JH, Postema K. Patients' expectations and actual use of custom-made orthopaedic shoes. Clin Rehabil. 2010;24(10): 919-27. [PMID:20576666] http://dx.doi.org/10.1177/0269215510367991

20. Hansen AH, Childress DS. Effects of shoe heel height on the roll-over shapes of prosthetic ankle-foot systems: Implications for heel-height-adjustable components. J Prosthet Orthot. 2009;21(1):48-54. http://dx.doi.org/10.1097/JPO.0b013e318191c902

21. Sam M, Childress DS, Hansen AH, Meier MR, Lambla S, Grahn EC, Rolock JS. The "shape\&roll” prosthetic foot: I. Design and development of appropriate technology for lowincome countries. Med Confl Surviv. 2004;20(4):294-306. [PMID:15688881] http://dx.doi.org/10.1080/1362369042000285937

22. Meier MR, Sam M, Hansen AH, Childress DS. The "shape\&roll” prosthetic foot: II. Field testing in El Salvador. Med Confl Surviv. 2004;20(4):307-25. [PMID:15688882] http://dx.doi.org/10.1080/1362369042000285946

23. Hansen AH, Childress DS. Investigations of roll-over shape: Implications for design, alignment, and evaluation of anklefoot prostheses and orthoses. Disabil Rehabil. 2010;32(26): 2201-9. [PMID:20626257] http://dx.doi.org/10.3109/09638288.2010.502586

24. Hansen AH, Childress DS, Knox EH. Roll-over shapes of human locomotor systems: Effects of walking speed. Clin Biomech (Bristol, Avon). 2004;19(4):407-14. [PMID:15109762] http://dx.doi.org/10.1016/j.clinbiomech.2003.12.001

25. Hansen AH, Childress DS. Effects of adding weight to the torso on roll-over characteristics of walking. J Rehabil Res
Dev. 2005;42(3):381-90. [PMID:16187250]

http://dx.doi.org/10.1682/JRRD.2004.04.0048

26. Wang CC, Hansen AH. Response of able-bodied persons to changes in shoe rocker radius during walking: Changes in ankle kinematics to maintain a consistent roll-over shape. J Biomech. 2010;43(12):2288-93. [PMID:20483413] http://dx.doi.org/10.1016/j.jbiomech.2010.04.036

27. Hansen AH, Sam M, Childress DS. The Effective Foot Length Ratio (EFLR): A potential tool for characterization and evaluation of prosthetic feet. J Prosthet Orthot. 2004; 116(2):41-45. http://dx.doi.org/10.1097/00008526-200404000-00002

28. Hansen AH. Roll-over characteristics of human walking with applications for artificial limbs [PhD thesis]. Evanston (IL): Northwestern University; 2002.

Submitted for publication January 18, 2013. Accepted in revised form November 7, 2013.

This article and any supplementary material should be cited as follows:

Meier MR, Tucker KA, Hansen AH. Development of inexpensive prosthetic feet for high-heeled shoes using simple shoe insole model. J Rehabil Res Dev. 2014; 51(3):439-50.

http://dx.doi.org/10.1682/JRRD.2013.01.0010
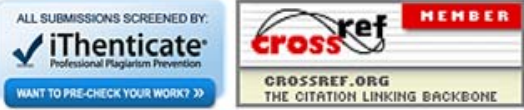